\title{
Can Internet Access Growth Help Reduce the Global Burden Of Noncommunicable Diseases?
}

\author{
Stefan Kohler ${ }^{1}$
}

1 Institute for Social Medicine, Epidemiology and Health Economics, Charité University Medical Center, Berlin, Germany

\begin{abstract}
Noncommunicable diseases, such as cardiovascular diseases, cancer, chronic respiratory diseases, and diabetes, are currently the leading causes of death in several regions of the world. The continuing fast increase in the global burden of noncommunicable diseases is accompanied by a speedy worldwide internet access growth. The worldwide number of internet users has doubled over the past five years. As the internet can make the access to information on a healthy lifestyle and disease prevention activities easier, internet access growth may help to promote good health. Against this background, I discuss the roles the internet and access to information can play in health promotion. I also present an open access web portal on local prevention and health promotion activities. It was initiated by two German states to link health information from disparate sources and to organize this information in a user-friendly way. The web portal focuses on reducing preventable lifestyle-related risk factors associated with noncommunicable diseases, including physical inactivity, unhealthy diet, tobacco use, and the harmful use of alcohol. This local initiative has the potential for scaling up and can serve as a blueprint for other areas that have or will acquire internet access.
\end{abstract}

Keywords: internet, health promotion, open access, prevention, scale up, web portal

Correspondence: stefan.kohler@charite.de

Copyright $@ 2013$ the author(s)

This is an Open Access article. Authors own copyright of their articles appearing in the Online Journal of Public Health Informatics. Readers may copy articles without permission of the copyright owner(s), as long as the author and OJPHI are acknowledged in the copy and the copy is used for educational, not-for-profit purposes.

\section{Introduction}

The three leading causes of death in 1900 were pneumonia, tuberculosis, and diarrhea and enteritis. Together with diphtheria, these diseases caused one third of all deaths. Heart disease, already at that time the most frequent noncommunicable disease (NCD) death, was estimated as the fourth most frequent cause of death (1). Nowadays, NCDs constitute the leading causes of death in all regions, except Africa (2). Nearly $80 \%$ of NCD deaths (29 million) in 2008 occurred in low- and middle-income countries (3). Cardiovascular disease, such as heart attacks and strokes, accounted for most NCD deaths (17 million) in that year, followed by cancer ( 7.6 million), respiratory diseases such as chronic obstructed pulmonary disease and asthma (4.2 million), and diabetes (1.3 million) (2). Taken together, these four groups of NCDs account for approximately $80 \%$ of all NCD deaths (30.1 million). The largest increases in NCD deaths by 2020 are projected for Africa, the Eastern Mediterranean and South-East Asia. In these regions, NCDs may increase by over 20\% (2). By 2030, the total annual number of deaths from NCDs may increase to 55 million, i.e., exceed the 2008 death toll by $50 \%$ (3). The four most common NCDs share lifestyle-related and preventable 
risk factors; notably, physical inactivity, unhealthy diet, tobacco use, and harmful use of alcohol $(2,4)$. According to the World Health Organization (WHO), 9\% of global NCDs deaths can be attributed to tobacco use, $6 \%$ to physical inactivity and $5 \%$ to overweight and obesity (4).

Besides the advance of NCDs and their influence on the causes of death, another rapidly evolving trend is shaping our lives. The number of internet users worldwide has doubled over the past five years. By the end of 2010, around 30\% of the world population was online (5). The proportion of households with internet access at home and of individuals using the internet were lowest in low-income countries (1.6\% and 5.7\%, respectively), moderately low in middle-income countries (17.8\% and $23.8 \%$, respectively), and highest in high-income countries $(74.0 \%$ and $73.6 \%$, respectively). These disparities have decreased since 2005 because the growth rates in the proportion of households with internet access at home and of individuals using the internet from 2005 to 2010 were highest in low-income countries $(300 \%$ and $418 \%$, respectively), moderately high in middle-income countries (147\% and $201 \%$, respectively), and lowest in high-income countries (37\% and $24 \%$, respectively) (Table 1 ).

Table 1. Households with Internet access at home and individuals using the internet

\begin{tabular}{|c|c|c|c|c|c|c|c|c|c|}
\hline & \multicolumn{3}{|c|}{ Population (mil.) } & \multicolumn{3}{|c|}{ Access $(\%)$} & \multicolumn{3}{|c|}{ Usage $(\%)$} \\
\hline & 2005 & 2010 & $\Delta$ & 2005 & 2010 & $\Delta$ & 2005 & 2010 & $\Delta$ \\
\hline Germany & 82 & 82 & 0 & 61.6 & 82.5 & 34 & 68.7 & 82.0 & 19 \\
\hline World & 6,504 & 6,895 & 6 & 18.8 & 30.3 & 61 & 15.8 & 30.2 & 91 \\
\hline East Asia \& Pacific & 1,893 & 1,962 & 4 & 9.0 & 19.8 & 120 & 8.3 & 29.8 & 259 \\
\hline Europe \& Central Asia & 399 & 405 & 2 & 6.7 & 34.3 & 412 & 12.9 & 39.3 & 205 \\
\hline Latin America \& Caribbean & 550 & 583 & 6 & 9.7 & 20.7 & 113 & 16.5 & 34.0 & 106 \\
\hline Middle East \& North Africa & 304 & 331 & 9 & 9.1 & 22.7 & 149 & 8.3 & 21.0 & 153 \\
\hline South Asia & 1,517 & 1,633 & 8 & 1.4 & 4.3 & 207 & 2.5 & 8.1 & 224 \\
\hline Sub-Saharan Africa & 755 & 853 & 13 & 1.1 & 3.6 & 227 & 2.3 & 11.2 & 387 \\
\hline Low income & 718 & 796 & 11 & 0.4 & 1.6 & 300 & 1.1 & 5.7 & 418 \\
\hline Middle income & 4,699 & 4,971 & 6 & 7.2 & 17.8 & 147 & 7.9 & 23.8 & 201 \\
\hline High income & 1,087 & 1,127 & 4 & 54.0 & 74.0 & 37 & 59.3 & 73.6 & 24 \\
\hline
\end{tabular}

Note: $\Delta$ Growth from 2005 to 2010 in percent

Data: World Bank \& International Telecommunication Union (5)

Observing that internet access and usage is growing in all regions of the world at a time when the global prevalence of NCDs is increasing, poses the question whether internet access growth can help reduce the global burden of NCDs; and if so, how? As the internet offers ways for the user to access, and for health professionals to present customized health information, its growth may help to strengthen prevention and health promotion worldwide; particularly in areas of the world that have or will obtain internet access and face an increasing burden of NCDs.

In this article, I discuss the roles the internet and access to information can play in health promotion. I also present an open access web portal on local health promotion and prevention activities, and its web statistics. The web portal presented was initiated by the two German states Berlin and Brandenburg in order to make existing information on regional disease prevention and health promotion activities more accessible and visible. Its ultimate goal is to thereby motivate more people in the region to pursue a healthier lifestyle. Despite the fact that the web portal was developed in a local initiative, the underlying idea and concept to inform about local health activities and a healthy lifestyle under one virtual roof have the 
potential for scaling up and can serve as a blueprint for other areas that have or will acquire internet access.

\section{The internet, access to information and health promotion}

The internet facilitates access to information from various sources. It may also create access to information for the first time. The internet allows information providers to distribute information rapidly and widely. It allows fast updates of information and the possibility of organizing information in appealing ways. Users are confronted with good and bad information, which they need to evaluate, for instance, by assessing the trustworthiness of the information provider or by comparing information from different, ideally independent, sources. If the challenge of assessing the quality of the information is successfully undertaken, then the information accessed through the internet enables people to make informed decisions about their life and health.

The relationship between access to information, which increases with internet growth, and health was acknowledged, for example, at the First International Conference on Health Promotion organized by the WHO and held in Ottawa in 1986. The resulting Ottawa Charter for Health Promotion characterized health promotion as the process of enabling people to increase control over and to improve their health. It recognizes that access to information, together with a secure foundation in a supportive environment enables people because: "People cannot achieve their fullest health potential unless they are able to take control of those things which determine their health," e.g., "a secure foundation in a supportive environment, access to information, life skills, and opportunities for making healthy choices" (6). The possible role of information and new information technology has been discussed and assessed, for example, by the WHO Regional Office for Europe: "Information and education [...] are necessary and core components of health promotion, which aims at increasing knowledge and disseminating information related to health. [...] The mass media and new information technologies are particularly important" $(7,8)$.

Subsequently, the broader term of health literacy, described by the WHO "as the cognitive and social skills which determine the motivation and ability of individuals to gain access to, understand and use information in ways which promote and maintain good health," has been brought into the discussion as a prerequisite of healthy behavior. "By improving people's access to health information and their capacity to use it effectively, health literacy is critical to empowerment" $(9,10)$. This need to not only be able to access, but also to understand and use information becomes apparent when looking at the amount of health information that can be accessed through the internet. A Google search of the web for the terms "prevention" or "health promotion" currently yields about 251 million results, and about 11 million results for the corresponding German terms "Prävention" and "Gesundheitsförderung." An web portal for prevention and health promotion activities as started in the German region BerlinBrandenburg is an example of how information on local prevention and health promotion activities and projects can become organized in order to be more visible and accessible.

\section{The web portal for prevention and health in Berlin and Brandenburg}

The internet is widespread and popular in Germany. A percentage of 82.5 of households can access the internet and $82 \%$ of households use the internet for an average time of 140 minutes per day $(11,12)$. Thus, a web portal for prevention and health promotion in this setting can potentially activate many people. Amongst other things, this may have encouraged the launch of a web portal dedicated to prevention and health promotion in Berlin and Brandenburg (http://praeventionsatlas.de/). It was initiated and is maintained by a common health economy 
network of the local governments of these two states (13). The goal of this web portal is to present information on a healthy lifestyle together with information on local health activities in an easy, accessible and visible way. The perceived need for presenting information on a healthy lifestyle and health activities in a new way, which is addressed by the web portal, is consistent with the following observation:

\begin{abstract}
Statutory health insurance, that serves over $80 \%$ the German population, subsidizes several health prevention and health promotion activities. The Social Insurance Code ( $\$ 20$ Sozialgesetzbuch V) sets a target value for primary prevention expenditure, which statutory health insurance follows. In 2011, the target value of $€ 2.86$ per insurant was exceeded by $35 \%$, resulting in a spending of $€ 270$ million on primary prevention courses and projects by statutory health insurance (14). Despite low costs to all those insured, the participation rate in these subsidized prevention courses is consistently low $(2.4 \%$ in 2011 and $3.0 \%$ in 2009) $(15,16)$. This suggests that, inter alia, there might be a need to improve the access to and impact of existing information on a healthy lifestyle and health activities, in addition to offering low-cost health activities.
\end{abstract}

All of the main topics under which German statutory health insurance actively sponsors lifestyle-related health courses and projects are covered by the web portal: e.g., physical activities, healthy diet, cessation of substance abuse, and stress management. Brief health tips for each topic are combined with information on corresponding and locally available health courses, as well as contact people (17-19). Stress is not one of the NCD risk factors enumerated by the WHO, but stress may aggravate unhealthy behavior, such as overeating or eating unhealthy foods, smoking or drinking, or directly trigger cardiovascular diseases (2022). In contrary, stress may not increase blood pressure (22) and, thus, not increase the prevalence of raised blood pressure, which the WHO describes as the leading NCD risk factor globally in terms of attributable deaths (4)

It is expected that an increased visibility of the information on local health activities derived from the web portal will lead to an increased participation rate in those activities as well as their proliferation. If these goals are achieved through the web portal, it can help reduce common NCD risk factors and, in consequence, the prevalence of NCDs. Active content management on the web portal facilitates the bridging of gaps between scientific evidence on preventive interventions and prevention practiced (23). Therefore, the web portal can support early communication of effective and up-to-date health advice. Regular web statistics implemented within the web portal allow the monitoring and evaluation of intermediate goals, such as the number of site visits and usage of the information on the web portal.

\title{
Web statistics
}

Web statistics enable an ongoing evaluation of the user access of and interests in the health information provided. The informational content can be revised promptly to counter a decline in user interest, as measured by the total number of website visits, or to guide users to specific topics in prevention and health promotion.

From its launch date, August 30, 2011, until July, 31, 2013, the web portal was visited by approximately one out of every 750 residents in the Berlin-Brandenburg region, accounting for a total of about 10,000 visits with more than three page views during an average site visit. Almost 5,000 further visits originated in other regions than Berlin or Brandenburg. Countries in which German is an official language accounted for $98 \%$ all visits. Within the BerlinBrandenburg region, $82 \%$ of all visits of the web portal are new visits compared to $84 \%$ worldwide. Interest in the topics substance abuse (12.53\%) and stress management $(21.86 \%)$, was lower than interest in topics healthy diet $(24.03 \%)$ and physical activity $(41.58 \%)$, on average over the past 23 months. Over time, interest in physical activity $(+0.60 \%, p<0.01)$ 
and healthy diet $(-0.56 \%, \mathrm{p}<0.01)$, as measured by monthly visits to the topic in the web portal, have changed significantly. This change may reflect that the behavior of the visitors to the website is still reaching its steady state. Interest in stress management $(+0.03 \%, p>0.75)$ and substance abuse $(-0.07 \%, \mathrm{p}>0.58)$ have remained constant (Figure 1$)$.

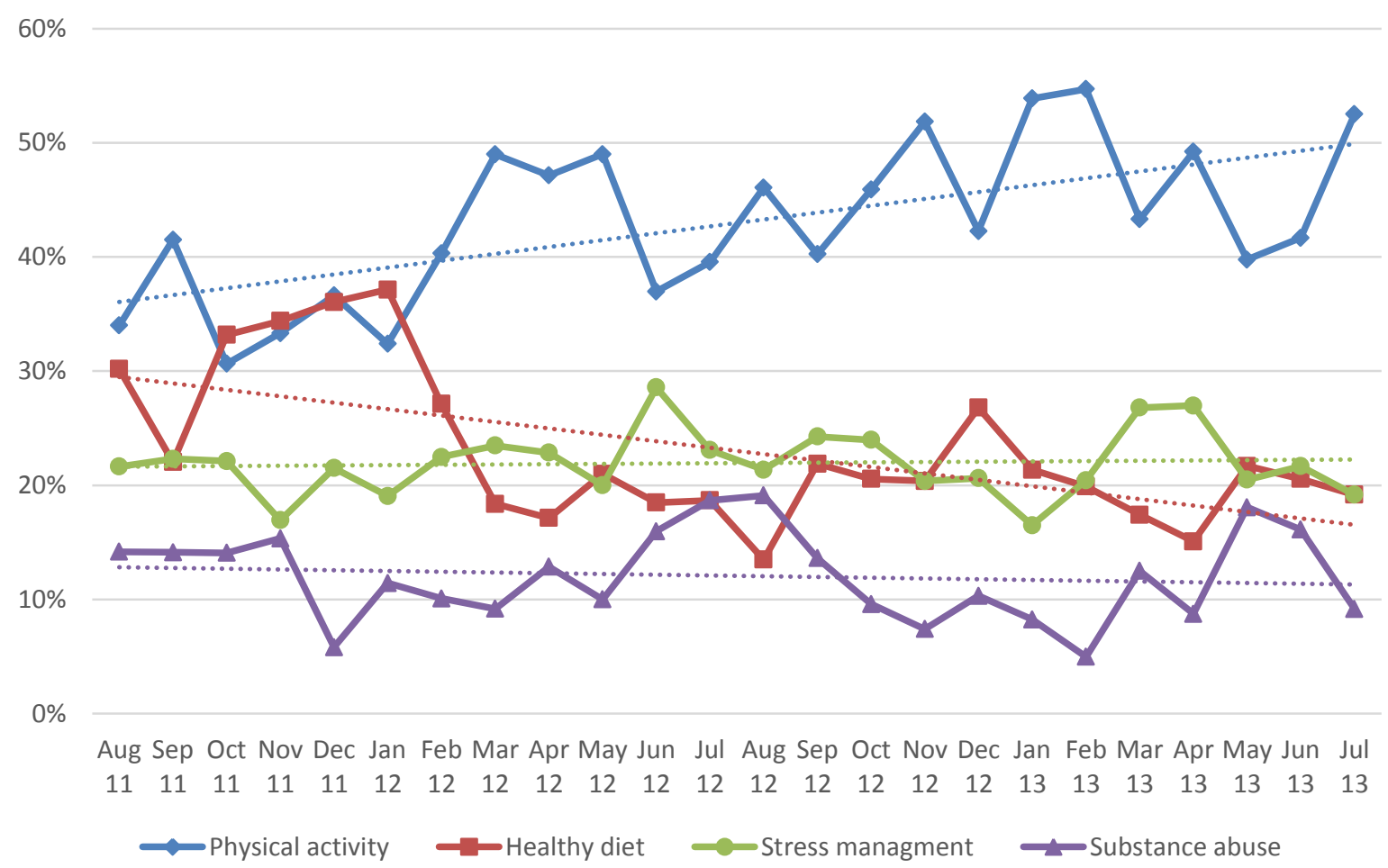

Figure 1. Interests of users and trends on web portal for prevention and health promotion in Berlin and Brandenburg (http://praeventionsatlas.de/)

Data: Google Analytics

\section{Discussion}

A web portal dedicated to disease prevention and health promotion activities that are available locally increases their visibility and may, thus, increase participation in those activities. In the case of Germany, several promotional subsidized health activities are available. In countries with different conditions, the development of an adapted web portal to strengthen disease prevention and health promotion could accompany a government's or organization's attempt to introduce interventions to improve health.

Informing about health activities through the internet may also help to attract some social groups who are underrepresented, such as young adults and males, to these activities: In 2011, 2.4\% of all those publicly insured in Germany participated in subsidized prevention programs offered by their health plan. The participation rate was below average for people younger than 30 years of age, who may feel less need to prevent disease than the elderly or consider the contents of the subsidized health activities unattractive. Of all participants, $21 \%$ were male and $79 \%$ were female $(14,24)$. By contrast, the internet usage shows a different trend. In 2012, according to an annual survey of 30,195 German citizens over 14 years of age, $81 \%$ of men and $70.5 \%$ of women were internet users; internet use decreased steadily 
with age from $98.7 \%$ (14-19 years) to $60.4 \%$ (60-69 years) and dropped sharply among the $70+$ age group (28.2\%) (11). Since internet usage by gender and age is inversely associated with participation in prevention courses by gender and age, informing about health activities through the internet may help to attract young adults and males, who are the more frequent internet users but have less interest in health promotion activities.

\section{Conclusion}

Taking into consideration the wide usage of the internet among Germans, the web portal for prevention and health promotion that exists in the states of Berlin and Brandenburg can increase participation in local prevention and health promotion activities in this region and among specific target groups. Due to the worldwide increase in internet access, the concept of an open access web portal for prevention and health promotion activities has the potential to be transferred to other regions including developing countries, which are confronted with the fastest internet proliferation and an increasing burden of lifestyle-related NCDs. The number of people with diabetes, for example, is projected to more than double between 2000 and 2030 in all regions of the world, except established market economies and former socialist economies, in which the projected increase is $54 \%$ and $20 \%$, respectively (25). This projection is consistent with a recent large epidemiological survey of 153,996 adults in three high-income countries, seven upper-middle-income countries, three lower-middle-income countries, and four low-income countries. It found that the prevalence of healthy lifestyle behavior was low among a sample of patients with a coronary heart disease or stroke event, with even lower levels in poorer countries (26).

In summary, the idea and concept behind the web portal for prevention and health promotion in Berlin and Brandenburg have the potential for scaling up. As more and more areas of the world have or will acquire internet access, organized information on healthy behavior and available options for personal action, made accessible through the internet, are likely to help reduce the burden of NCDs globally.

\section{Acknowledgments}

No sources of funding were used to prepare this article. The author was part of a research team that developed the content of the 2011 edition of the web portal and a book on prevention and health promotion in Berlin and Brandenburg that were funded by the Senate for Economics, Technology and Women of the City of Berlin.

\section{Corresponding Author:}

Stefan Kohler, $\mathrm{PhD}$

Institute for Social Medicine, Epidemiology and Health Economics

Charitè University Medical Center

Luisenstraße 57

10098 Berlin

Germany

Email: stefan.kohler@charite.de

\section{References}

1. Centers for Disease Control and Prevention. Achievements in public health, 19001999: Control of infectious diseases. Morbidity and Mortality Weekly Report. 
1999;48(29):621-9.

2. Alwan A, editor. Global Status Report on Noncommunicable Diseases. Geneva: World Health Organization; 2011. 162 p.

3. Global Action Plan for the Prevention and Control of Noncommunicable Diseases. Geneva: World Health Organization; 2013. 38 p.

4. World Health Organization. Noncommunicable diseases: Fact sheet [Internet]. 2013 [cited 2013 Jul 31]. Available from: http://www.who.int/mediacentre/factsheets/fs355/en/index.html

5. World Bank, International Telecommunication Union. The Little Data Book on Information and Communication Technology 2012. Washington, DC: World Bank; 2012. $239 \mathrm{p}$.

6. World Health Organization. Ottawa Charter for Health Promotion. Health Promotion. 1986;1(4):iii-v.

7. Milestones in Health Promotion: Statements from Global Conferences. Geneva: World Health Organization; 2009. 35 p.

8. World Health Organization. A discussion document on the concept and principles of health promotion. Health Promotion. 1986;1(1):73-6.

9. World Health Organization. Health literacy and health behaviour [Internet]. [cited 2013 Jul 31]. Available from:

http://www.who.int/healthpromotion/conferences/7gchp/track2/en/index.html

10. Health Promotion Glossary. Geneva: World Health Organization; 1998. 36 p.

11. Initiative D21, TNS Infratest, editors. (N)ONLINER Atlas 2012: Basiszahlen für Deutschland [(N) ONLINER Atlas 2012: Basic figures for Germany]. Berlin: Initiative D21; 2012. 9 p.

12. BITKOM. Jeder Dritte geht in jeder freien Minute online [Every third person goes online in every spare minute] [Internet]. 2012 [cited 2013 Jul 31]. Available from: http://www.bitkom.org/de/markt_statistik/64026_72066.aspx

13. Cluster Gesundheitswirtschaft Berlin-Brandenburg - HealthCapital. Prävention und Gesundheitsförderung in Berlin und Brandenburg [Prevention and health promotion in Berlin and Brandenburg] [Internet]. [cited 2013 Jul 31]. Available from: http://www.praeventionsatlas.de/

14. Schempp N, Jung C, Seidel J, Strippel H. Präventionsbericht 2012 - Leistungen der gesetzlichen Krankenversicherung: Primärprävention und betriebliche Gesundheitsförderung [Prevention report 2012 - Benefits of the statutory health insurance: Primary prevention and workplace health promotion]. Essen: Medizinischer Dienst des Spitzenverbandes Bund der Krankenkassen; 2012. 124 p.

15. Schempp N, Seidel J. Tabellenband zum Präventionsbericht 2012 - Leistungen der gesetzlichen Krankenversicherung: Primärprävention und betriebliche Gesundheitsförderung [Appendix of the prevention report 2012]. Essen, Germany: Medizinischer Dienst des Spitzenverbandes Bund der Krankenkassen; 2012. 71 p.

16. Zelen K. Tabellenband zum Präventionsbericht 2010 - Leistungen der gesetzlichen Krankenversicherung: Primärprävention und betriebliche Gesundheitsförderung [Appendix of the prevention report 2010]. Essen: Medizinischer Dienst des Spitzenverbandes Bund der Krankenkassen; 2010. 63 p.

17. Willich SN, Nocon M, Müller-Nordhorn J. Gesundheitskurse in Berlin und Brandenburg: Atlas zur Prävention [Health courses in Berlin and Brandenburg: Atlas of prevention]. Berlin: HealthCapital Berlin Brandenburg; 2008. 88 p.

18. Kohler S, Müller-Riemenschneider F, Willich SN. Prävention und Gesundheitsförderung in Berlin und Brandenburg [Prevention and health promotion in Berlin and Brandenburg]. Berlin: HealthCapital Berlin Brandenburg; 2011. 102 p.

19. Kohler S, Nocon M, Müller-Riemenschneider F, Reinhold T, Willich SN. Der Präventionsatlas Berlin-Brandenburg: Strukturierte Informationen zu Prävention und 
Gesundheitsförderung [The Berlin-Brandenburg Altas of Prevention: Structured information on prevention and health promotion]. In: Kirch W, Hoffmann T, Pfaff H, editors. Prävention und Versorgung. Stuttgart: Thieme; 2012. p. 138-47.

20. Emeny RT, Zierer A, Lacruz ME, Baumert J, Herder C, Gornitzka G, et al. Job strainassociated inflammatory burden and long-term risk of coronary events: Findings from the MONICA/KORA Augsburg case-cohort study. Psychosomatic Medicine. 2013 Apr;75(3):317-25.

21. Stress in America: Missing the Health Care Connection. Washington, DC: American Psychological Association; 2013. 60 p.

22. Nyberg ST, Fransson EI, Heikkilä K, Alfredsson L, Casini A, Clays E, et al. Job strain and cardiovascular disease risk factors: Meta-analysis of individual-participant data from 47,000 men and women. PLOS ONE. 2013;8(6):e67323.

23. Reinhold T, Kohler S. Prävention und Gesundheitsförderung in Berlin und Brandenburg: Ein Präventionsatlas gibt Orientierung bei der Vielzahl verschiedener Gesundheitsangebote [Prevention and health promotion in Berlin and Brandenburg: An atlas of prevention gives orientation]. Gesundheitsstandort Berlin-Brandenburg. Berlin: Kulturbuch-Verlag; 2012. 51 p.

24. Gesundheitsberichterstattung des Bundes. Mitglieder und mitversicherte Familienangehörige der gesetzlichen Krankenversicherung am 1.7. eines Jahres [Members and insured family members of the statutory health insurance on 1.7. of a year] [Internet]. 2013 [cited 2013 Jul 31]. Available from: http://www.gbe-bund.de/

25. Wild S, Roglic G, Green A, Sicree R, King H. Global prevalence of diabetes: Estimates for the year 2000 and projections for 2030. Diabetes Care. 2004;27(5):104753.

26. Teo K, Lear S, Islam S, Mony P, Dehghan M, Li W, et al. Prevalence of a healthy lifestyle among individuals with cardiovascular disease in high-, middle- and lowincome countries: The Prospective Urban Rural Epidemiology (PURE) study. Journal of the American Medical Association. 2013;309(15):1613-21. 